\title{
How, Why, and About What Do Federal Prisoners Complain: And What We Can Do About It Miguel Zaldivar *
}

\section{INTRODUCTION}

Federal prisoners ${ }^{1}$ spend a large part of their day complaining about prison conditions. In fact, complaining about things such as meals, commissary and boredom is a major pastime for the bulk of the Federal Bureau of Prisons (BOP) population. However, what many of my fellow prisoners fail to grasp is that they sometimes contribute to the very prison conditions they complain about.

That current and former prisoners embellish their crimes and prison experiences is well documented. Not only is the average Joe behind bars inclined to telling colourful "war stories", but also convict authors such as Edward Bunker, Jack Abbot and Michael Santos have sensationalized their writings for what is known in the literary world as "effect". These raconteurs have done an exceptional job of selling the now infamous "convict bogeyman", and are in part responsible for the myths surrounding crime and corrections (Ross, 2008, p. 17).

Granted, other groups such as the mass media have also contributed to the unsavoury views society holds of crime and corrections (ibid). However, the majority of these groups are not immediately privy to what life behind bars is "really" like. These outlets often rely on the prisoners they report on and profit from their information. Unfortunately, the prison anecdotes passed on to these groups are often sensationalized for either a few dollars or minutes of fame. Thus, it seems ironic that those prisoners who have endured the sting of the correctional beast continue to promote images of crime and corrections that are not only deleterious to their own well-being, but also to the future survival of more than 2.3 million men and women behind bars (Fathi, 2011).

In this auto-ethnographic paper I first highlight three important and interrelated prison conditions prisoners complain about - crowding, staff members and other prisoners. These conditions not only negatively affect prisoners and staff members, but also threaten the security and orderly running of an institution. Second, I argue that prisoners are among the primary creators of this environment. By succumbing to the Convict Code's way of life, prisoners fetter their personal development and compound the odds of becoming recidivists. Their return trip to the penitentiary exacerbates the 
very conditions they complain about. Lastly, I provide what I believe to be the most efficacious solution available to my fellow prisoners. After twentyfour years of incarceration, I find that pointing to external circumstances for our troubles is a waste of time. Scholars and prisoner authors have long expounded on the injustices of the criminal justice system. Yet, as evident by the rising number of prisoners and the exorbitant rate of recidivism, the body of work of these well-intentioned individuals has accomplished little. Therefore, we must stop waiting on others to do for us what only we can do for ourselves. It is time we start taking responsibility for our past behaviour, as well as our present and future well-being.

\section{Overview}

In his benchmark study, The Society of Captives: A Study of a Maximum Security Prison, Gresham Sykes (1958) warns against discussing the prison experience from a collective prisoner perspective. With uncanny perspicacity, Sykes points out that each prisoner develops a unique interpretation of life behind bars. He suggests that, due to the individualized needs and backgrounds each prisoner brings to the institution, it can be "argued that in reality there are as many prisons as there are prisoners" (ibid, p. 63). Despite this caveat, however, Sykes exposes the existence of a "hard core of consensus expressed by the members of the captive population with regards to the nature of their confinement" (ibid). Bearing this understanding, I advance my observations of life within the walls and razor-wired fences of the Federal Bureau of Prisons.

The public may find it difficult to believe that a relatively small group of prisoners not only dictates, but also defines, "what is" and "what is not" acceptable prison behaviour. Nevertheless, the sad reality is that through peer pressure, the threat of or use of violence, and the corrupt tenets of the Convict Code, ${ }^{2}$ a small, self-interested group of prisoners not only terrorizes the general prison population into submission, but also perpetuates a prison culture that devours the men who are ensnared in its web. Indeed, the tentacles of the Code are so overwhelming that even white-collar criminals begin walking, talking and acting like hardened convicts within a short period of entering a federal prison. Truly, the time frame in which the transformation from "fish" to "convict" takes place is frightening.

However, in most cases, the transmutation is nothing more than a convenient façade. The majority of prisoners succumb to the Convict 
Code way of life not because they actually metamorphosed into hard-core prisoners, but rather because: 1) the Code allows prisoners to passively and safely express discontent over prison conditions; 2) it provides a historical (and some would say credible) podium from which to pass on embellished "war stories"; and 3) it offers a safe haven from the more predatory elements of the general prison population. The latter of these motivates most prisoners to adopt the Code's tenets as quickly as possible because they fear that failure to do so may result in them being ostracized, being labeled a "rat" and, in some extreme cases, being physically and/or sexually assaulted.

In sum, I have witnessed how through peer pressure, the use of violence, and the corrupt tenets of the Convict Code, a relatively small group of prisoners, consisting of less than ten percent of the prison's population and composed primarily of active gang members, coerces the general prison population into acting and behaving in ways that perpetuate the very prison conditions prisoners complain about. Ironically, what the vast majority of prisoners fail to grasp is that by succumbing to the Code's way of life, they are fueling the criminal incubator that not only breeds their present prison conditions, but also threatens their future freedom.

\section{Correctional Journey}

My correctional journey commenced outside of the United States. In 1988, I spent eight hellish months at Her Majesty's Prison (a.k.a. Fox Hill) in Nassau, Bahamas. Then shortly after being released from Fox Hill, I was held for five tormenting months at El Reclusorio de Hermosillo, Sonora, Mexico. These distinctly different experiences not only left lasting impressions, but also educated me on how debasing prison life can be and provided the correctional acumen to navigate the rough years that were soon to come.

My walk with the BOP began on May 9, 1990, and ever since then I have been a studious, but reluctant, guest of the federal prison system. I am a nonviolent, first-time offender serving thirty years for conspiracy to import, possess and distribute over ten tons of cocaine. And even though I forced the government into not one but two district court trials and appealed both my cases all the way to the United States Supreme Court, today, after many years of soul searching, I make no bones about admitting I am guilty of the charges brought against me.

While in the custody of the BOP I have been housed in four United States Penitentiaries (Leavenworth, Florence, Atlanta and Coleman 1), two 
Federal Correctional Institutions (Edgefield and Coleman-Medium), three Federal Detention/Transfer Centers (Miami, Tallahassee and Oklahoma), one Medical Center for Federal Prisoners (Springfield), and numerous city and county jails from as far west as Salt Lake City, Utah, to the southeast shores of Broward County, Florida to the capital's sordid D.C. Jail.

Shortly after arriving at USP Leavenworth (October 1991), I realized life behind the wall is all about making choices; I could either "click up" and waste the next twenty-five years of my life, or I could invest in myself and pursue a college education - I chose the latter. During my incarceration, I have earned two baccalaureate degrees from regionally accredited universities. ${ }^{3}$ I have completed over fifty cognitive/behavioural programs and educational courses. Since 2003, I have been a Suicide Companion, and from 2002 to 2006, I was a speaker for FCC Coleman USP1's Community Outreach Program. In addition, I spent seven years in the BOP's Skills Program working and living with "special needs inmates". During those years, I mentored and tutored emotionally and psychologically disturbed prisoners, mediated problems among participants, and facilitated courses such as Criminal Thinking Elimination, Breaking Barriers, Victim Impact and Stinky Thinking. Through these experiences, I learned a great deal about the BOP, my fellow prisoners and myself. However my trek with the BOP has also experienced hiccups along the way.

Throughout my incarceration, I have spent nearly five years in Special Housing Unit (SHU), more commonly known as "the hole". Some of those "time outs" I deserved, such as for my 1991 ill-advised and disastrous escape attempt from the Metropolitan Correctional Center in Miami, Florida, while others were thrown upon me due to no fault of my own. For example, while at USP Leavenworth, I was placed in SHU over a fictitious escape plot contrived by a disgruntled BOP captain. After a number of refusals to remove me from the High Accountability Security Program, I decided to go over the captain's head. The assistant warden of custody agreed with my request and instructed the captain to take me off the program. I quickly realized I had won the battle, but lost the war.

In retaliation, within six weeks I was thrown in SHU and transferred to another institution. In fact, the fallout from this incident led to my continuous detention in SHU for over two years while being transferred through three different institutions and eventually returned to where I started, at USP Leavenworth. But regardless of why I ended up in SHU, the experience and savvy-ness I gained from those excursions are priceless. 
In short, throughout my correctional journey, I have been an avid student of my environment, as well as of the men and women I interact with daily. I am what some people call an "insider", well-versed as to what life behind bars is really like.

\section{Crowding}

Over the last three decades, living conditions in the BOP have significantly deteriorated. Long gone are the days when federal prisoners lived in sparsely populated cellblocks, enjoyed palatable meals and bragged about well-stocked commissaries. Today, federal prisoners are fortunate if they are not tripled bunked, find a few vegetables in their meals, and are able to purchase seasonal fruits from commissary every now and then.

Several interrelated factors account for the overall difficulties consuming the BOP. For example, budgetary cuts, high employee turnover rate, and lower hiring standards. Yet, probably no single factor is more salient than the crowded conditions plaguing the federal prison system.

Crowding has various causes. For example, the Sentencing Reform Act of 1984 (SRA), which launched the Federal Sentencing Guidelines, introduced mandatory minimums, decreased good-time awarded, and eliminated parole for federal prisoners, is blamed for the overcrowded conditions ravaging the BOP (Fathi, 2011). In addition, stringent and punitive community supervision policies have also received much attention for their contributions to the crowding enigma (Richards and Jones, 2004). Therefore, to argue that these juridical and administrative determinants have not played significant roles would be puerile.

Be that as it may, these factors are beyond the immediate control of any single prisoner and to continue complaining about these factors does not appear to have ameliorated the crowding situation. On the contrary, blaming external circumstances not only frees prisoners from accepting responsibility for their contribution to the problem, but also hinders them from taking corrective action. Indeed, the blame game solidifies the "victimhood" mindset that compounds the likelihood of prisoners becoming recidivists, which in turn exacerbates the crowded conditions they complain about. However, there is one decisive factor prisoners do have control over that can alleviate, or at least contain, the crowding problem - the exorbitant rate of recidivism. ${ }^{4}$ 
Recidivism is an animal that has been studied and assailed from every angle imaginable. Yet, over the last four decades no meaningful reduction in the rate of this beast has been achieved. On the contrary, the rate of recidivism has steadily risen throughout the years.

There have been two major studies conducted on recidivism over the last forty years. The first looked at 108,580 men and women who were released from prison in 1983 (Beck and Shipley, 1989), and the second tracked 272,111 former prisoners released in 1994 (Lagan and Levin, 2002). Both studies used similar methodology and followed the participants for the same extended period after release - three years. That these studies reached analogous conclusions is startling. However, even more alarming is the fact that the rate of recidivism rose five percentage points over a mere eleven year period - from 62.5 percent in 1989 to 67.5 in 2002 (Langan and Levin, 2002). If we extrapolate this number over the last twenty years, we can easily say the rate of recidivism is fast approaching the eighty percent mark. Granted, this is an overly simplistic view of an extremely complicated phenomenon. Nevertheless, the point here is not to dwell on the mechanics of said conclusion, but rather to emphasize the fact that the deck is stacked against prisoners when it comes to making a successful re-entry.

That recidivism is a major contributor to prison crowding is a no-brainer. The fact that four out of ten prisoners are re-arrested within one year of being released and seven out of ten within three clearly underscores this point (Langan and Levine, 2002, p. 3). Yet, little is heard regarding this link. Why are people so reluctant to connect the dots? The BOP's prison population consists of a 35/65 split between first-timers and repeat criminalized persons (FPP: A Statistical Analysis), which means that out of the more than 220,000 federal prisoners at least 150,000 are recidivists. These facts should be enough to convince even the most ardent opponents of this reality. Still, few scholars are willing to examine this link. Convict authors conveniently overlook the issue and individuals who mean well, find it un-American to hold the recidivist accountable for his or her contribution to the crowding equation. In fact, some members of these groups go as far as to portray recidivists as mere victims of a callous and punitive judicial system, and argue that crowding is the product of "the structural realities of prison conditions and re-entry[...] and not the criminal or deviant behaviour of individuals" (Richards and Jones, 2004, p. 202). These scholars de-emphasize the fact that recidivists, like all members of free society, are legally responsible for their actions and have ultimate say-so over the decisions they make. 
Are there exceptions to this socially accepted convention? Of course there are. The mentally incompetent, for instance, are held to a less rigorous legal standard (Cooper v. Oklahoma, 1996). This, in most cases, allows them to receive special treatment from the criminal justice system. A case in point is that of my older brother, Roly, who only served six months in a federal medical facility instead of the twenty years he would have done if he had not be declared mentally incompetent to stand trial. However, in my experience, I have found that the overwhelming majority of recidivists (and prisoners in total) are fully cognizant of the decisions they make. But regardless of one's position on this matter, the fact remains that to ignore the recidivist's role in the crowding riddle is not only irresponsible, but also foolishly dangerous.

Crowded prison conditions affect much more than the sleeping arrangements and meals of the prisoner population. Indeed, crowded conditions not only trigger most of the problems/issues staff must deal with on a daily basis, but also ignite the majority of the difficulties prisoners complain about (Ross, 2008).

The effects of crowding are felt long before the institution reaches its maximum rated capacity (Allen, 2004). In general, crowding leads to less educational, vocational, and recreational opportunities for the prison population. Also, crowding means there are less institutional jobs available, leaving a large number of prisoners with little to do. This idleness induces boredom and generates a great deal of frustration (Ross, 2008). And one thing is certain - bored and frustrated prisoners are dangerous prisoners. In fact, "the rate of death, suicide, homicide, inmate assault, and disturbances increase as prison population density increases" (Allen, 2006, p.169). Moreover, this finding holds regardless of whether prisoners are "confined in maximum, medium, or minimum security" institutions (ibid).

Crowded prison conditions also affect the little things prisoners must deal with daily. For example, crowding means prisoners have less access to things such as telephones, computers, televisions, showers and even visiting privileges. These little things may seem trivial, but a large number of prisoner/prisoner assaults arise over such petty things as the use of a telephone or the changing of a television channel. Furthermore, these incidents not only are happening more frequently, but also are evolving into more serious confrontations as "homeboys" and gang members get dragged into the mix. 
Lastly, crowded prison conditions lead to greater health risks for both staff and prisoners. Diseases such as tuberculosis and hepatitis are easily transmitted. Crowding not only facilitates the spread of these diseases, but also makes them very difficult to treat since it is impossible to isolate infected prisoners when there is no place to put them (Ross, 2008).

In short, there is no doubt federal prisoners have a legitimate complaint when it comes to the crowded prison conditions pillaging the BOP. Crowding not only makes prison life more challenging, but also exposes both staff and prisoners to extremely dangerous situations. Unfortunately, this prisoner complaint garners little public or government sympathy because the complainers themselves are major contributors to the crowding situation. By choosing to re-offend and/or violate conditions of supervised release and returning to prison, whether in the face of structurally difficult life circumstances or not, recidivists encumber the crowded conditions they complain about. Granted, as highlighted above, other factors such as the Sentencing Reform Act of 1984, the Federal Sentencing Guidelines, and the stringent community supervision policies enforced by probation and parole agencies have also significantly contributed to the overcrowding conditions. Nevertheless, these juridical issues are beyond prisoners' control, and for us (prisoners) to keep blaming them for the crowded conditions we endure without accepting, or at least acknowledging, our contribution to the problem is problematic.

\section{Staff Members}

Staff is a subject of much discord and entertainment among prisoners. Prisoners enjoy maligning staff and complaining about lazy case managers, antagonistic correctional officers (COs) and incompetent work supervisors. If you let prisoners tell it, you would think a bunch of cretins and simpletons run the BOP. Yet, in fairness to these prisoners, the BOP does employ its share of all of the above. Still, the negative perception prisoners have of staff cannot be adequately explained by the employment of a few bad apples - other factors are at work here.

Over the last fifteen to twenty years, staff's treatment of prisoners has lapsed considerably. There are several reasons for this. For example, the BOP has experienced an exodus of its most qualified and educated personnel. Too many top-tier employees have abandoned the BOP for more 
challenging, better paying and less stressful jobs. In addition, budgetary cuts have coerced the BOP into "pushing out" senior staffers who earn higher wages than incoming employees do in similar positions. These factors have the Feds scraping the bottom of the barrel for potential hires and have forced the BOP to operate its facilities with less qualified and experienced CO's. ${ }^{5}$

Other factors affecting prisoners' perception of staff are the result of the staff problems/issues mentioned earlier; specifically, less educated and experienced staff lack the skills to properly manage unruly prisoners. Furthermore, throughout the last decade I have witnessed how understaffing not only has exacerbated the problem, but also has become the Achilles' heel of the BOP.

To make up for staff shortage, the BOP is forcing officers to work longer hours and to man more than one post at a time. For example, at FCC Coleman - Medium COs are frequently pressed into working "doubles", that is, backto-back shifts. In fact, understaffing is so prevalent at FCC Coleman that posts are not even manned unless they are considered "mission critical". Add to this the responsibility of supervising more than one housing unit at a time, and one begins to understand why COs are more irritable and less willing to deal with prisoner nuisances. This situation has created a great deal of stress, cynicism and even deviance as COs cut corners to get their jobs done, generating a host of complaints from the prisoner population. Thus, these factors not only compromise the safety and orderly running of the institution, but also affect prisoners' perceptions of staff.

With this said, are prisoners' complaints regarding lazy case managers, antagonistic COs, and incompetent work supervisors grounded in facts or are prisoners just maligning staff because it is the "convict" thing to do? Before answering this question, it is worth remembering that life in prison is all about perception. Unfortunately, the perception of most prisoners is skewed by the omnipresence of the Convict Code. To illustrate how the Convict Code warps prisoners' perception of staff members and other prison complaints, let us examine a common occurrence I have endured since May 2006.

FCC Coleman-Medium announces prisoner "work call" at 7:30 a.m. Over the public address system (PA), the entire prison population is treated to the sound of, "Work-call, Work-call. All inmates up the middle, shirt tails tucked in, I.D.'s out". To get to my work assignment, I, along with approximately 400 other prisoners, have to travel a distance that is twice as long as the return 
trip back to the housing units. This is because instead of turning right at the first available sidewalk leading to UNICOR, kitchen, facilities, education, and the like, we are made to walk "up the middle" (straight ahead) toward the compound shack where several officers watch us parade by, making sure our shirt tails are tucked in and that we display our prison identification cards. This exercise takes place every weekday morning (excluding holidays), rain or shine. Therefore, one would think that after several weeks of this, prisoners would deduce that this routine is not going to change regardless of the amount of complaining they do. Yet, the outcries invariably begin as soon as we approach that first available right.

As we near the first intersection, some prisoner will say something to the effect of, "This is fucking ridiculous. It makes no fucking sense to walk all the way around". Then someone else will add, "These assholes (staff) are on a power trip. Bet these bitch-ass motherfuckers pull rank here because they can't do it at home". Of course this badmouthing of staff generates some laughter and several "Ain't that the truth", along with other similar forms of agreement. This nonsense goes on for the eighty or ninety yards leading up to the compound shack; from there, these rants become more personal.

As we approach the compound shack, from somewhere along this moving queue we hear, "There is that punk Smith", referring to Officer Smith. ${ }^{7}$ Then someone else will say something like, "You know he likes to feel you up when he shakes you down". And sure enough, as we walk past the staff members, Officer Smith singles out some prisoner who for whatever reason believes that the instructions announced over the PA system do not apply to him. At this point, with hundreds of prisoners watching, Officer Smith orders the transgressor to turn around and proceeds to pat him down. Consequently, this scene corroborates the views regarding Officer Smith that have been heard by a large number of prisoners. Thus, after several days of listening to this verbal garbage and witnessing similar scenes, it comes as no surprise that the vast majority of prisoners internalize vituperative views of Officer Smith. Before you know it, through rumours and innuendos, Officer Smith is perceived as an antagonistic $\mathrm{CO}$ who also harbours homosexual tendencies.

However, let us sprinkle a sense of reality to the above events by briefly addressing the following questions: 1) What purpose does complaining about and/or disparaging Officer Smith serve? 2) Who benefits the most from this prison ritual? 3) How does it affect the general prison population? 
The most salient purpose behind the grousing and decrying of staff members is a prisoner's need to be accepted by his peers. While the human need for social acceptance is natural and instinctive, in prison this becomes a counterproductive and destructive force. Moreover, by voicing his discontent, a prisoner hopes to dispel any thought of him being weak and expatiates the belief that his show of solidarity against Officer Smith will keep the predators off his back.

The prisoners who benefit the most - at least from a prison culture perspective - are those who belittle staff on a regular basis. The majority of prisoners perceive these vocal individuals as the "bad asses" of the compound, the ones who do not give a damn about rules and regulations. In effect, by constantly speaking out and engaging in confrontations with staff, these prisoners climb up the distorted and, in my experience, quite delusionary hierarchical structure of the Convict Code.

Finally, the general prison population is affected in several ways. However, none is more pernicious than the cunning fashion in which it is coerced into acting and behaving in ways that support the views of the most stentorian complainers, who usually are self-proclaimed adherents of the Convict Code. This leads many prisoners to adopt attitudes, habits, beliefs, and expectations that are counterproductive to their present well-being and future freedom. For many prisoners, either out of peer pressure or the threat of and/or use of violence, succumbing to the Code's way of life is a means of surviving the prison experience and to be accepted by their peers. Unfortunately, what most prisoners fail to grasp is that said way of life not only fetters their personal growth while incarcerated, but also compounds the odds of them becoming recidivists. Simply put, the attitudes, habits, beliefs and expectations that function in a prison setting are not transferable to the free world. Moreover, these inimical prison attributes do not just magically transform and/or vanish as prisoners walk out the front door. In fact, I suspect that it is precisely the attitudes, habits, beliefs and expectations that prisoners nurture while incarcerated that land 7 out of 10 of us back in prison within three years of being released.

Therefore, after peppering a healthy dose of reality into the mix, it is easy to appreciate how the Convict Code skews prisoners' perception of staff members and other prison complaints. Most prisoners complain about lazy case managers, antagonistic correctional officers, and incompetent supervisors because they believe it is expected of them since it is perceived 
as the convict thing to do, and not because a bunch of cretins and simpletons run the BOP. Still, to deny that the BOP employs all of the above would miss the mark.

In summation, the Convict Code facilitates three important functions: 1) the Code allows prisoners to passively and safely express discontent over prison conditions; 2) it provides a historical podium from which to pass on embellished war stories; and 3) it offers a safe haven from the more predatory elements of the prison population. Accordingly, prisoners tend to complain about staff members simply because most believe it is expected of them. Complaining about lazy and incompetent staff not only provides a safe way of expressing frustration over prison conditions, but also allows prisoners to play up the "convict" role in the presence of their peers. Through their complaints, prisoners express solidarity and, more importantly, display their allegiance to the Code.

Prisoners complain about staff members for a number of reasons. However, probably no reason is more salient than a prisoner's desperate need to fit into a hostile environment that preys on weakness and individuality. The BOP does employ a number of lazy, difficult and incompetent staff members. And, unfortunately, the number of these shady employees will continue to rise as the BOP lowers its hiring standards. However, until this small minority becomes at least a majority of one, it behooves us not to mislead the public. Besides, exaggerating staff's shortcomings is not going to alleviate our present living conditions. On the contrary, it can only make matters worse.

\section{Other Prisoners}

Complaining about other prisoners is natural in a prison setting. Think about it. Anytime thousands of men are thrown together in a confined space and forced to interact differences are going to arise. However, over the last ten to fifteen years, complaints regarding other prisoners have soared. Several factors account for the increased grumbling. Yet, the most conspicuous is the fact the BOP has been housing a more criminally diverse clientele.

Up until the mid 1990's, the BOP's prison population consisted of the "cream of the crop" of the underworld: international drug traffickers, upper echelon organized-crime members, professional thieves and white-collar criminals. During that time, the majority of prisoners were well-educated 
and many were multilingual with worldly experience (Richards, 2005, p. 189). The type of crimes these men typically engaged in were in line with what criminologists refer to as "rational" and "instrumental" (Brown, et al., 2004, p. 29). In addition, prisoners of old not only tended to be conscientious in their dealings with others inside, but also were cognizant of the possible consequences their behaviour provoked from both staff and others who are incarcerated.

In contrast, many of today's BOP prison population is made up of uneducated, ill-mannered, and incorrigible petty criminals. This new generation of criminals tends to engage in "expressive" and "mala in se" type of crimes (ibid, p. 28). Not only do they lack the education and manners of their predecessors, but they also enjoy engaging in prison behaviour that is both irritating and dangerous to other prisoners. But, before addressing some of these behaviours, it is worth emphasizing three factors that account for the overall discrepancies between the prisoners of old and those of this new generation.

First, over the last twenty-five years a large number of crimes that once were under the bailiwick of local and state governments have been federalized (Ehrlich, 2000). During this period, I have noticed that an increasing number of men have entered the federal systems for crimes such as crack jacking, sexual offenses and small quantities of drugs. Historically, local and state governments have pursued these types of crimes. However, from the increased presence of these prisoners, it is obvious that the federal government has been vigorously prosecuting crimes it once regarded outside of its judicial purview. Second, the closure of the District of Columbia's correctional system pushed nearly 15,000 prisoners into the BOP (Washington Post, 2006).

The majority of these men are serving sentences for an assortment of crimes ranging from first-degree murder to petty theft. Moreover, the arrival of D.C. prisoners introduced into the BOP a variety of quirks unlike anything the feds had ever experienced. From my interaction with these men, I have determined that a large number of them are difficult for the BOP to manage and extremely challenging for the general prison population to get along with. Finally, the recent national witch-hunt against illegal immigration has generated a large number of uneducated prisoners, some of whom have extensive ties to gangs such as the Mara Salvatrucha (MS13), Aztecas and Border Brothers (Vaughan and Feere, 2008). 
The foreign prisoners who fall into this category present special challenges for both staff and prisoners because the vast majority of them do not speak English and are associated with violent street gangs. Adding to this is the fact that most of these gangs are usually warring with one another and trying to keep up with who is beefing with who is an exercise in futility. Accordingly, these factors are largely responsible for the differences between the prisoners who were considered "the cream of the crop" and those of the new breed presently being warehoused by the BOP.

But what are some of the prison behaviours that are causing so much discontent among prisoners? Below I address three forms of prisoner behaviour that not only generate a great deal of complaining, but are also exacerbating the deterioration of relations with staff.

\section{Prisoner Duplicity}

Throughout the history of corrections COs and prisoners have engaged in a "cat and mouse" relationship. Prisoners have always tried to get away with as much as possible, while COs diligently worked to maintain some semblance of order. For the most part, both parties played by the rules and neither side pushed the other too far for fear of excessive retaliation. However, even within this Gordian convention prisoners of old carried themselves respectfully and understood the concept of "my word is my bond". In fact, the relationship between staff and prisoners was so well established that I can recall numerous occasions where staff turned to them to help resolve conflicts between rival gangs, among prisoners, and even between staff and prisoners. Unfortunately, today this is no longer the case.

Today, staff is cognizant that some members of this new generation of prisoners are all about 'rocking its enemy to sleep'. Officers realize that this recalcitrant group of individuals is only concerned about getting over on 'the man', regardless of the costs or consequences their actions may provoke the rest of the prison population by prison administrators. This fact is most evident in the number of privileges federal prisoners have lost over the last ten to fifteen years. For instance, at my present institution, FCC Coleman-Medium, commissary no longer sells hard candy, sugar or fresh fruits because these items are regularly used to cook wine. Additionally, prisoners and their families no longer have access to the outside visiting patio because of the selfish antics of a few prisoners who are more interested in five-minute thrills than the well-being of their peers. These little things 
may seem trivial, but for old prisoners that have spent decades behind bars and some who will never get out, they make all the difference in the world.

\section{Indiscriminate Violence}

Violence is embedded in prison life. And how can it not be? We throw together thousands of men from all walks of life and expect them to play nice. However, the violence I witnessed two decades ago was well-organized and motivated by the desire to correct a perceived wrong rather than by the act itself. Furthermore, old cons understood that violence was to be avoided because 1) it tends to escalate, especially between gangs, and 2) it only serves to "bring down more heat" on the rest of the prison population. Only the gravest of Code infractions merited the use of violence and then only after it had been sanctioned by the appropriate bodies.

In contrast, today's violence often lacks organization/structure, which means it is carried out haphazardly with little consideration as to how it will affect the rest of the prison population. Moreover, today's violence is perpetuated for the simple pleasure of the act itself. Taken together, this new twist on prison violence not only has undone what little respect staff once held for prisoners, but also has fostered a dog-eat-dog world where prisoners are more prone to resolve difference through violence than by parleying things out. This environment has led to greater distrust and hostility among prisoners and has contributed to the deterioration of staff/prisoner relations.

\section{Sexual Misconduct}

The introduction of female COs into the prison cellblocks has coincided with an epidemic of sexual misconduct. As more women have taken up what traditionally was considered a male posting, the number of prisoners receiving incident reports for stalking, indecent exposure, making sexual proposals, and sexual assault continues to be a challenge. Three interrelated causes account for this phenomenon.

First, I have noticed that the posting of female officers in housing units has increased the level of interaction between female staff and male prisoners. This protracted socialization has led to greater familiarization, which is not necessarily negative, but has provided more opportunities for sexual misconduct. Second, over the last several years the number of prisoners serving sentences for sexual offenses has nearly doubled, from 5,700 in May 2008 to 11,229 as of March 2013 (FBOP Quick Facts). Most of these 
prisoners, whose programming needs are arguably not met by authorities, seem to experience difficulty controlling their sexual urges, which makes them more prone to push the limits of what the BOP beholds as acceptable interaction between male prisoners and female staff members. Lastly, longer sentences means a larger number of prisoners have spent years (in some cases decades) without the companionship of the opposite sex. Some of these men are serving life sentences and are cognizant they will die in prison. Many of these prisoners feel they have little to lose by propositioning or, in some extreme cases, sexually assaulting a female staff member.

Hence, the collaboration of these causes appears to have increased the number of incident reports for sexual misconduct and also has deteriorated the symbiotic relationship that staff and old prisoners once enjoyed. Twenty years ago it was rare to hear that a prisoner was caught "gunning down" (the act of masturbating and/or exposing yourself) a female staff member. Today, this practice is very much en vogue, especially at the USP level. Unfortunately, this sort of behaviour not only creates a great deal of tension between staff and prisoners, but also generates a host of difficulties for the general prison population. For instance, a prisoner who keeps his hands inside his pant pockets for too long while in the presence of a female staff member is subject to be labelled a "gunner" and is dealt with accordingly.

In short, many younger federal prisoners tend to be deceptive, violent and disrespectful toward both staff and their fellow prisoners. Trying to talk sense to this new breed often feels like a waste of time. Therefore, it should come as no surprise that complaining about other prisoners is a major pastime for the majority of the BOP's prison population. However, the conundrum most prisoners fail to grasp is that the most vocal complainers are oblivious to the fact that they are the "other inmate" their peers complain about. In the end, complaining about other prisoners serves one vital function - it allows complainers to point their fingers at others for the prison conditions they themselves have helped create.

\section{Solutions}

The most efficacious solutions to prisoners' complaints are as simple as they are complex. Simple because prisoners have the wherewithal to change the prison conditions they complain about, and complex because, unfortunately, not enough of my peers are willing to accept responsibility 
for their past, present, and future behaviour, which is necessary to effect any meaningful change.

Accepting responsibility for our behaviour means acknowledging our contributions to the prison conditions we have helped create. It also means coming to terms with the fact that blaming external circumstances for our plight is a difficult business given the structural change in American society that is required. Scholars, prisoner authors, and well-meaning individuals can continue to point to all of the injustices committed by the criminal justice system, the flawed penology that led to the abandonment of the medical model of corrections, and whatever other social, economic, and political factors they deem responsible for the prison conditions we endure. However, these arguments have been vocalized over the last thirty years. And what has been accomplished? We presently have over 2.3 million men and women behind bars, at an estimated annual cost of over forty billion dollars (Ross, 2008, p. 61). We have approximately another five million individuals under some form of correctional control (Ross, 2013, p. 14). If these numbers do not awaken in us a sense of urgency regarding the conditions we find ourselves in, then I have no idea what will. So as I see it, we (prisoners) can either continue to wait for others to bring about the correctional and systematic changes they claim will liberate us from our miserable existence or we can take our lives and futures into our own hands. The bottom line is that no one is going to do for us what we are more than capable of doing for ourselves.

The first thing we must stop doing is passing on exaggerated versions of our criminal and correctional experiences. We need to understand that by embellishing our "war stories" and focusing on the worst of our prison experiences, we are perpetuating distorted images of who we (prisoners as a whole) really are. These warped images are used by the media, the entertainment industry, the government, and even some university professors to champion a malicious process known as "deviance amplification". Books such as Santos' Inside: Life Behind Bars in America and "reality" television shows like Lockup only serve to create what sociologists refer to as a "moral panic". Moral panics are used to manipulate the masses by corroborating the twisted images society already holds of a particular issue; in this case, of crime and corrections.

But this is not to say that bad things do not happen in prison - of course they do! However, what prison writers such as Bunker, Abbot and Santos 
have done is sensationalize the worst aspects of prison behaviour, which moral entrepreneurs use to justify their "tough on crime" posturing and policy making. In other words, some of our most popularized "storytelling" and our participation in skewed documentaries not only make the government's job easier but also facilitate the very prison conditions we complain about.

Second, we must make an individual and concerted stand against the tenets of the Convict Code. By succumbing to the Code's way of life and by allowing a small group of prisoners to dictate "what is" and "what is not" acceptable prison behaviour, we are not only fueling the prison conditions we complain about, but also guaranteeing for ourselves a round-trip ticket back to the penitentiary. We have to make it clear to this group of prisoners that we will not succumb to peer pressure, nor will we allow their threat of and/or use of violence to dictate our behaviour. Moreover, we must fight off the prison attitudes, habits, beliefs and expectations that have enslaved them to a life of misery. Indeed, we must simply refuse to become the hard-core, recidivist monsters they and the prison-industrial-complex wish to make of us.

Finally, we must stop blaming external circumstances for our predicaments. We are already cognizant that the Sentencing Reform Act of 1984 and other systematic factors have played significant roles in our lives. We have seen how these draconian laws have contributed to the deterioration of the federal prison system. However, with the exception of civil disobedience, we have no control over these juridical issues, nor do we have a say over the budgetary and staffing problems affecting the BOP. Therefore, why continue pointing to these issues as if by doing so they will magically disappear and our problems will go away? Instead, let us focus on what we can actually do to bring about the changes we desire.

Recidivism is the only factor of the correctional carrousel we have control over. And as demonstrated above, recidivism plays a significant role in the prison conditions we complain about. Hence, while incarcerated, we must do all we can to improve our odds of making a successful re-entry. How do we go about this? First, by accepting responsibility for our present and future well-being, and second by acquiring the social and job skills necessary to better our lives.

Throughout my incarceration, I have found that two factors account for most of the recidivists I have met: 1) the lack of employment opportunities for ex-prisoners and 2) the proliferation of substance abuse among my peers. Fortunately, the BOP offers numerous courses and programs aimed 
at helping prisoners develop the job skills they need and at assisting them overcome whatever addiction(s) they are struggling with.

\section{Employability of Former-Prisoners}

The fact that former prisoners have a more difficult time finding employment than the average citizen cannot be denied. In 2010, the Center for Economic and Policy Research conducted a study, which revealed "that a felony conviction or imprisonment significantly reduces the ability of ex-offenders to find jobs". Adding to this difficulty is the fact that prisoners are less educated, have less work experience, and lack social skills such as the ability to relate to people or be punctual (CEPR, 2010). All these factors contribute to the poor employability of former prisoners. However, I have found that with a little work and a steady dose of persistency these shortcomings can be overcome.

The foundation of a successful re-entry lies in our present willingness to make ourselves more attractive to employers upon release. This means that if a lack of education has been the weak link in your resume, then you must make your way to the education department and earn your General Equivalency Diploma (GED). If computers seem alien to you, get down to V. T. (Vocational Training) and take the Microsoft course. If your communication skills leave much to be desired, enrol in a public speaking class. In other words, take advantage of all the educational and vocational opportunities offered by the BOP.

In addition, through the BOP's Federal Prison Industry (UNICOR) ${ }^{8}$ program, you can gain marketable job skills that can lead to viable and sustainable employment upon release (FBOP, 2012). I am aware the vast majority of prisoners do not want to participate in UNICOR, and that is unfortunate. Because even though UNICOR is a prison program that operates at a perennial financial loss and is known for its slave-labour wages, ${ }^{9}$ research shows that those "inmates who work in UNICOR are twenty-four percent less likely to return to prison than their counterparts who did not participate in the UNICOR program" (Saylor and Gaes, 1997). These practical steps may seem insignificant, however, in the long run they may very well determine whether we make a successful re-entry or be counted as one more recidivist.

\section{Overcoming Substance Abuse}

Sixty percent of recidivists blame drug/alcohol abuse for their re-offending or violating supervised release (Pelissier et al., 2000). But here again the 
BOP offers several cognitive/behavioural programs that teach prisoners about "addiction" and provide practical tools to help them conquer their personal demons.

For example, the Residential Drug Abuse Program (RDAP) has been shown to lower both the rate of relapse and the rate of recidivism (Pelissier, 2000). RDAP is a 500-hours, unit-based program that keeps participants separated from the rest of the general prison population so that they can work together to create a community that supports pro-social attitudes and behaviours (BOP, Psychology Treatment Program, 2009). The aim of separating RDAP participants is so they can be kept away from the negative peer pressures of the larger prison environment (a.k.a. the ubiquitous Convict Code).

Other mental health treatment programs offered by the BOP include the Bureau Rehabilitation and Values Enhancement Program (BRAVE), the Skills Program, and the Axis II Program. These programs not only teach prisoners about the pitfalls of chemical dependency, but also challenge participants to examine their criminal thinking and antisocial behaviours.

Before closing this section, it is worth emphasizing that the success or failure of the above solutions is predicated on one simple but crucial element: a prisoner's readiness to accept responsibility for his or her past, present and future behaviour. Once this obstacle is overcome, I have found that then he or she can begin the painful, but rewarding, journey of "honestly [discovering] who he or she is and what he or she wants to be, and do the [necessary] work to accomplish the change" (Richards and Jones, p. 227). However, let us not kid ourselves. When all is said and done, it is not the programs we completed or the education and job skills we acquired while incarcerated that will determine our success or failure in the free world albeit these things help - but rather the individual choices and decisions we make. In the end, we must all be cognizant that it all begins with us, and it all ends with us.

In sum, the solutions to our complaints are within our grasp. Unfortunately, I have noticed that too many of us lack the courage to speak out against the injustices we endure at the hands of our peers. For far too many of us, it is much easier to succumb to the Convict Code's way of life and to go along with prison rituals than to stand apart and face the wrath of all the foolishness around us. Sadly, this conduct is evident from the fact that seven out of ten of us find our way back to prison within three years of release. 


\section{Conclusion}

Passing on exaggerated versions of our "war stories" and focusing on the worst of our prison behaviour is not going to improve the correctional conditions we complain about. On the contrary, these distorted images supply the ammunition moral entrepreneurs need to justify their "tough on crime" policy and legislation recommendations, which in turn exacerbate our present conditions and relegate us to second-class citizens upon our release. Our embellishments may provide the "effect" the literary world demands, and may even pad the wallets of those fortunate enough to have their work published. However, in the real world these colourful stories negatively "affect" the present and future survival of more than 2.3 million men and women behind bars.

In addition, wasting our time in front of idiot boxes and complaining about juridical issues beyond our control is asinine. If we want to effect changes within the Federal Bureau of Prisons, then we must stop waiting on others to do for us what only we can do for ourselves. By bettering ourselves we will not only improve our odds of making a successful re-entry, but also do our part to ease the prison conditions we complain so much about.

Finally, I want to address those prisoners who so willingly succumb to the Convict Code's way of life and so readily adopt the prison attitudes, habits, beliefs, and expectations that practically guarantee your return trip to the penitentiary. I know how difficult it is to stand apart from all the nonsense we endure on a daily basis. But despite these challenges, I encourage you to do so.

\section{ENDNOTES}

* I would like to thank the following individuals. My parents, Margarita and Rolando Zaldivar, for believing in me even when I did not believe in myself. My children, Michelle, Priscilla and Michael Zaldivar, for their generous assistance and input; Michi, I could not have done it without your help. Dr. Justin Piché for this invaluable opportunity and support throughout the writing process, as well as the anonymous reviewers for their time, comments and suggestions, and their willingness to work with me. Your comments fuelled my desire to see this project through. The prisoners at FCC Coleman USP1, MEDIUM, and LOW are also acknowledged for putting up with my ceaseless prodding and probing. I hope I remained loyal to your views. And last, but by no means least, I would like to express my deepest gratitude to Dr. Jeffrey Ian Ross. Professor, this paper is as much yours as it is mine. I thank you for 
all the time, patience, guidance, teachings, and understanding you have provided throughout the years. I am forever in your debt.

1 Throughout this paper I use the term "prisoner" rather than "inmate". I do this out of consideration for the work of the men and women who make up the Journal of Prisoners on Prisons and the school of Convict Criminology. I also refrain as much as possible from using the term "convict" because regardless of the contentions of some Convict Criminologists (See Richards, 2005, p. 193), I believe the term, as defined by Charles Huckelbury (2009, pp. 24-25), breeds a mindset that causes more harm than benefit in the lives of more than 2.3 million men and women behind bars.

2 The Convict Code is a set of rules by which prisoners live. For example, prisoners are to mind their own business, have access to a weapon at all times, stab rats, and kill child molesters, look out for homeboys, stay away from punks (homosexuals), and are absolutely not to socialize with staff.

3 In 2002, I was awarded a Bachelor of Science in Business Administration from Saint Mary College (Leavenworth, Kansas) and in 2008 a Bachelor of Science in Sociology/Criminology from Colorado State University (Pueblo, Colorado).

4 Recidivism is here defined as "re-incarceration", regardless of whether it is due to reoffending and/or violating conditions of supervised release. It is also noted that the term "recidivism" is a "complex phenomenon that is difficult to define and measure" (Ross, 2008, p. 140). It is further acknowledged that "Most men and women who go back to prison do so for [probation and] parole violations" (Ross and Richards, 2009, p. xi). Still, none of these factors alter the dynamics of the overcrowding riddle. Whether we (prisoners) return to prison for new crimes or probation and/or parole violations does not change the fact there are simply too many of us behind bars.

5 Personal conversations with staff members at FCC Coleman-Medium. The names of officers have been omitted at their request.

6 See endnote 5.

7 A fictitious name created to facilitate the writing/reading process.

8 The BOP's Federal Prison Industries, Incorporated (FPI), better known as UNICOR, is a wholly-owned government corporation. UNICOR was created, in part, by President Franklin D. Roosevelt's Executive Order 6917, issued on December 11, 1934. (BOP, Factories with Fences, 2012)

9 Working in UNICOR earns a prisoner between $\$ .23$ to $\$ 1.65$ per hour depending on pay grade and longevity.

\section{REFERENCES}

Allen, Harry F., Clifford E. Simonsen and Edward J. Latessa (2004) Corrections in America: An Introduction, Upper Saddle River (NJ): Pearson Prentice Hall.

Beck, Allen J. and Shipley, Bernard E. (1989) Recidivism of Prisoners Released in 1983, Bureau of Justice Statistics, U.S. Department of Justice. NCJ-116261.

Brown, Stephen E., Finn-Aage Esbensen, and Gilbert Geis (2004) Criminology: Explaining crime and its context (5th ed.). Study Guide, Cincinnati (OH): Anderson Publishing Co. 
Center for Economic and Policy Research (2010) Ex-Offenders and the Labor Market November. Retrieved from www.thegrio.com.

Cooper v. Oklahoma [1996] 517 U.S. 348.

Ehrlich, Susan A. (2000) "The Increasing Federalization of Crime", Arizona State Law Journal, 825: $825-841$.

Fathi, David (2011) "Custody vs. Treatment Debate. Addicted to Punishment", National Liberator, 15(3): 12.

Federal Bureau of Prisons (2012) "Factories with Fences", Federal Bureau of Prisons Office of Research and Evaluation - March.

Federal Bureau of Prisons (no date), Quick Facts About the Bureau of Prisons. Retrieved from www.bop.gov/news/quick.jsp.

Langan, Patrick A. and David J. Levine (2002) Recidivism of Prisoners Released in 1994, Bureau of Justice Statistics, U. S. Department of Justice, NCJ 193427.

Huckelbury, Charles (2009) "Talking Points: How Language Functions as a Status Determinant in Prison", Journal of Prisoners on Prisons, 18(1\&2): 22-28.

Pelissier, Bernadette, William Rhodes, Wiliam Saylor, Gerry Gaes, Scott D. Camp, Suzy D. Vanyur, and Sue Wallace (2000) "TRAID Drug Treatment Evaluation Project", Final Report of Three-Year Outcomes Federal Bureau of Prisons Office of Research and Evaluation.

Richards, Stephen C. (2005) "Born Illegal”, Storytelling Sociology: Narrative as Social Inquiry, in Ronald J. Berger and Richard Quinney (eds.), Colorado: Lynne Rienner Inc., pp.183-193.

Richards, Stephen C. and Richard S. Jones (2004) "Beating the Perpetual Incarceration Machine: Overcoming Structural Impediments to Re-entry", in Shadd Maruna and Russ Immarigeon (eds.), After Crime and Punishment: Pathway to Offender Reintegration Cullompton, Devon: Willan Publishing, pp. 201-232.

Ross, Jeffrey Ian (2013) "Invention of the American Supermax Prison", in Jeffrey Ian Ross (ed.), The Globalization of Supermax Prisons, New Jersey: Rutgers University Press, pp. 10-24.

Ross, Jeffrey Ian (2008) Special Problems in Corrections, Upper Saddle River, New Jersey: Pearson Education Inc.

Ross, Jeffrey Ian and Richards C. Richards (2009) Beyond Bars: Rejoining society after prison, Alpha Books, New York (NY): Penguin Group Inc.

Saylor, William G. and Gerald G. Gaes (1997) "Post Release Employment Project", Correctional Management Quarterly, 1(2).

Sykes, Gresham M. (1958) The Society of Captives: A Study of a Maximum Security Prison, Princeton University Press: Princeton Paperback, 1971.

The Sentencing Project (no date) The Federal Prison Population: A Statistical Analysis., retrieved from www.sentencingproject.org.

U. S. Department of Justice (2009) Federal Bureau of Prisons, Psychology Treatment +Program. P5330.11 Washington (DC): BOP.

Vaughan, Jessica M. and Jon D. Feere (2008) "Taking Back the Streets: ICE and Local Law Enforcement Target Immigrant Gangs", Center for Immigration Studies, Washington, DC (www.cis.org).

Washington Post (2006) "Lorton, From Prison to Parkland" - March. Retrieved from http:// www.washingtonpost.com/wpdyn/content/article/2006/03/22/AR2006032200860.html. 


\section{ABOUT THE AUTHOR}

Miguel Zaldivar is a first-time, nonviolent prisoner in his twenty-fourth year of a thirty- year sentence for drug related crimes. While incarcerated, Zaldivar has earned baccalaureate degrees in Business Administration and Sociology/Criminology. He has also completed over fifty cognitive/ behavioural programs and educational courses. For the last decade, he has served as a Suicide Companion. From 2002 to 2006, he was a spokesperson for FCC Coleman USP1's Community Outreach Program. He is currently at Federal Correctional Complex Coleman Low. 